\title{
Activity spaces Measures of social exclusion?
}

\section{Working Paper}

\section{Author(s):}

Schönfelder, Stefan; Axhausen, Kay W. (1)

Publication date:

2003-01

Permanent link:

https://doi.org/10.3929/ethz-a-004492887

\section{Rights / license:}

In Copyright - Non-Commercial Use Permitted

Originally published in:

Arbeitsberichte Verkehrs- und Raumplanung 140 


\section{Work place}

$\circ$

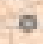

\section{Main shopping location}

Submitted to Transportation Policy

Activity spaces: Measures of social exclusion ?

Stefan Schönfelder and Kay W. Axhausen 
Working paper

\title{
Activity spaces: Measures of social exclusion?
}

\author{
Stefan Schönfelder and Kay W. Axhausen \\ IVT \\ ETH Zürich \\ CH-8093 Zürich
}

Telephone: 0041-1-633 3943

Telefax: 0041-1-633 1057

axhausen@ivt.baug.ethz.ch

January 2003

\section{Abstract}

The paper provides a first investigation of the suitability of different measures of activity space size to identify persons at risk of social exclusion. This would be a new departure for the measurement of social exclusion which so far has relied either on aggregate measures of locations or cross-sections data of individuals.

The size of a person's activity space can only be estimated with information reflecting a longer time horizon. In this paper the six-week travel diary survey (Mobidrive) is used, which was conducted in the two German cities in 1999. About $90 \%$ of all local trips were coded for 300 respondents (about 45000 trips).

The paper develops three possible measurement approaches of increasing complexity (confidence ellipse, kernel density estimates, minimum spanning trees). The analysis revealed that the main driver of the size of the activity spaces is the overall number of unique locations visited by the respondents and, to a lesser extent, their socio-demographic characteristics. In particular, the groups most often considered to be at risk of social exclusion (female, lower income, elderly) did not show significantly different activity spaces.

\section{Keywords}

Activity space - Measures - longitudinal travel data - Mobidrive - Social exclusion - ETH Zurich - Institute for Transport Planning and Systems (IVT)

\section{Preferred citation style}

Schönfelder, S. and K.W. Axhausen (2002) Activity spaces: Measures of social exclusion?, Arbeitsbericht Verkehrs- und Raumplanung, 140, Institut für Verkehrsplanung und Transportsysteme (IVT), ETH Zürich, Zürich. 


\section{Social exclusion: A point of departure}

In recent years policy making in Europe has added the category "Social Exclusion" to its repertoire of problem descriptions. As an inherently multi-facetted concept it lacks a strong definition (see the discussion in Hine and Mitchell, 2002), but most authors imply a regular physical and social exclusion from the resources of a dignified life: an active labour market, good quality health care and consumption opportunities, and, finally, integration in the wider networks of civic life. The relative (good, active, wider) and qualitative terms (dignified) make it clear, that social exclusion is defined, if at all, through local and regional political processes in which the relevant yardsticks are agreed.

The proposed conceptualisation makes it also clear that social exclusion is not the same as poverty, or social isolation or physical distance. It is often combined with these more easily measurable characteristics, but does not have to be. Examples are easy to construct.

The transport and land use system can reinforce social exclusion by increasing the generalised cost of travel for persons at risk. If persons find themselves in circumstances where their home location relative to the transport services (low speeds, large distances to stops or stations, large distances to possible places of work, service and consumption) and their available mobility tools (car ownership/access, public transport season ticket ownership) (See Hägerstrand, 1970) increase these costs (i.e. the psychologically weighted sum of travel times, out-of-pocket costs and comfort) relative to the population average, then they are less likely to engage in travel and are therefore less likely to participate fully in society. While low generalised costs of travel do not assure social inclusion, they make it easier to achieve.

This link has been the focus of the transport policy debate on social exclusion which will not be reviewed here given the other papers in this issue of Transport Policy. Supporting this debate has been a growing and now substantial literature on aggregate measures of transport disadvantage (Church, Frost and Sullivan, 2001; DETR, 2000; Gibb, Kearns, Keoghan, MacKay and Turok, 1998) While it is possible to map generalised costs differences and the implied differences in accessibility, it is hard to link those to the incidence of social exclusion given its multi-dimensional nature. As Grieco, Turner and Hine (2000) have pointed out, there is no logical need for the socially excluded to concentrate spatially. They can equally well be scattered among the population at large. This undermines the value of many mapping based exercises.

In contrast, there has been little thinking about the use of data on the personal use of space (physical and social), as an indicator of social exclusion. This paper wants to add to this discus- 
sion by reporting initial measurements of the activity spaces of a sample of residents in two German cities (Karlsruhe and Halle).

Activity space is that part of the environment which a traveller is using for his/her activities (see Golledge and Stimson, 1997 for a comprehensive overview). It can be thought of as an approximation of the mental map of the traveller (see e.g. Lynch, 1960 or Downs and Stea, 1977 for early work on this issue). The mental map is one of three approaches used to describe a traveller's personal world in the literature. The other two are the activity repertoire (Axhausen, 1998) and the expectation space. The mental map stresses the spatial knowledge about activity opportunities and their relative positions and connections, while the activity repertoire looks at the type, quality and costs of different activities or activity types at different locations. The expectation space is the sum of the generalisations with which the traveller works in uncertain or unknown locations and circumstances: expected speeds on different types of roads, the facilities to expect at an airport, the set of stores around an underground station or the likely responses of public transport operators in the face of delays or cancellations.

In a wider sense, the mental map comprises both those locations of which a traveller has personal experience (activity space), as well as those of which the traveller has second hand experiences through family, friends, books, films or other media (the knowledge space) (see e.g. Horton and Reynolds, 1971; Dürr 1979 or Goldenberg, Libai and Muller, 2001).

The discussions of social exclusion link the social aspect to the physical aspect, i.e. that socially excluded persons are also excluded from certain parts of the environment, mostly through the high generalised costs they face in reaching particular locations, or any location for that matter. The lack of exposure to certain places is linked to lower chances in the job markets, more restricted social networks (and therefore fewer "weak" links (Granovetter, 1973)) and higher costs of living, as cheaper peripheral big format stores are out of reach or relatively speaking more difficult to reach. This reasoning makes the measurement of the activity spaces of persons or groups of persons an attractive, albeit indirect, indicator of their level of social inclusion. It is indirect in two ways: it ignores other forms of communication (visits to the person, phone, letter and all forms of internet-based communications), which can to some extent replace physical contact. In addition, as mentioned above, the activity space is only an approximate measure of the size of the mental map, i.e. of the locations and opportunities known to the traveller. The paper will return to the question of the quality of this approximation below.

The early literature in transport and geography on activity spaces was based on cross-sectional data for groups of respondents (for examples see Kutter, 1973; Zahavi, 1979; Beckmann, Golob and Zahavi, 1983a,b; Holzapfel, 1980; Scheiner, 2001, but see Dijst, 1999 for a rare estimate of individual activity spaces). Treating many cross-sections as a quasi-panel of an average person (type) is problematic, as it ignores the biographical elements in the mental map of an individual 
and is likely to bias the conclusions. Still, until recently no data sets of sufficient duration were available, which would have reasonably allowed an estimate of the size of individual activity spaces. While GPS-based tracking exercises now allow the collection of data sets of nearly arbitrary duration, in essence duplicating work which has a long tradition in biological research, this paper is based on a long duration travel diary survey, the 6-week Mobidrive diary (Axhausen, Zimmermann, Rindsfüser, Schönfelder and Haupt, 2002). To our best knowledge, this study is the first to analyse human activity spaces based on individual panel data.

The aim of the paper is to test whether the sizes of the observed activity spaces can be linked to the socio-demographic characteristics of the respondents. If successful, one could use this measure to characterise the differences between different groups of travellers, but in particular, socially excluded travellers. It has to be pointed out here that the Mobidrive sample was not constructed with this question in mind, in particular no attempt was made to sample socially excluded persons in particular. Any results will therefore be indicative and not conclusive.

The structure of the paper is as follows: the next section introduces the survey followed by a discussion of three possible measures of the size of an activity space. The core of the paper is a set of models linking measured size to the socio-demographics of the persons. The conclusions address the questions formulated in the title of this paper and further research needs.

\section{The Mobidrive travel data: Data structure and address geocoding}

The Mobidrive project was designed to obtain a more detailed picture of mobility patterns and to develop methodological approaches to capture behavioural variability (see Zimmermann, Axhausen, Beckmann, Düsterwald, Fraschini, Haupt, König, Kübel, Rindsfüser, Schlich, Schönfelder, Simma and Wehmeier, 2001; Axhausen et al., 2002). Based on the experiences made with a similar survey in the 1970s (Uppsala Household Travel Survey, see e.g. Marble, Hanson and Hanson, 1972), a continuous six-week travel diary survey was conducted for Mobidrive in the German cities of Halle/Saale and Karlsruhe in autumn $1999^{1}$. A total of 317 persons over 6 years in 139 households participated in the main phase of the survey after testing the survey instruments in a pre-test with a smaller sample in spring 1999. The paper-based travel-diary instrument

${ }^{1}$ Both cities have about 300’000 inhabitant, large universities, very well developed public transport systems (Karlsruhe, especially so - see Brandl and Axhausen, 1999) with high service frequencies to all parts of the cities and are relatively freestanding. The levels of income and unemployment are rather different reflecting the loss of the traditional chemical industry in Halle after reunification. 
was supplemented by further survey elements providing a unique level of socio-demographic detail for surveys of this type (see Axhausen et al., 2002 for a detailed description of the survey) ${ }^{2}$.

\section{Address geocoding}

One objective of the Mobidrive consortium was to provide exact locational data in order to facilitate the analysis of the variability in spatial behaviour over time. This data was obtained by geocoding the trip destination addresses of all trips of the main study (approximately 40.000 trips). The addresses - including home and workplace locations - were transformed into GaussKrüger coordinates in a WGS 84 (World Geodetic System) geodetic reference system. The geocoding was possible for about $95 \%$ of the reported trips.

Due to incomplete addresses and limited availability of digital address information outside the urban cores of the case study regions, the geocodes of the addresses have different degrees of resolution for the different spatial units. For the municipalities City of Karlsruhe and City of Halle, the street addresses could be geocoded on the basis of (small) building blocks (i.e. more than $90 \%$ of all geocoded trips), whereas outside the urban boundaries the addresses are available as geocodes of the centroids of the municipality, only. This has of course implications for any spatial analysis as the geocoding does not yield a $100 \%$-exactness for the locational data - especially for non-local trips. The number of unique locations can be assumed to be slightly higher than what is revealed by the data. Furthermore, the fact that trip destinations outside the city boundaries are aggregated to one single $x$-y-coordinate restricts the interpretation spatial analysis results. Consistent results can be only expected for the local part of the overall mobility. As most of the ongoing investigations are of a comparative character, though, this lack of precision can be accepted.

In addition to the georeferenced trip data, there is selected digital land use and transport network information available for both case study cities. This allows the combining of travel demand and supply data for the behavioural analyses (see Schönfelder and Axhausen, 2002 for details).

\section{Measuring activity spaces}

Activity space is that part of the daily environment which is used by a traveller (see also Axhausen, 2002). Related concepts such as the action space (e.g. Horton and Reynolds, 1971), the awareness space (e.g. Brown and Moore, 1970), the perceptual space (e.g. Dürr, 1979), mental maps (e.g. Lynch, 1984) or space-time prisms (e.g. Lenntorp, 1976) describe the individual po-

\footnotetext{
${ }^{2}$ The data are available from the Sozialwissenschaftlichen Datenarchiv at the University of Cologne. See in addition www.ivt.baug.ethz.ch/daten
} 
tentials of travel - based on spatial knowledge, mobility resources, the objective supply of opportunities etc. Activity space may defined as a two-dimensional form which is constituted by the spatial distribution of those locations a traveller has personal experience (contact) with (see Figure 1 for a schematic representation).

The geometry, size and inherent structure of activity spaces are determined by mainly three determinants (Golledge and Stimson, 1997, 279):

- Home: The position of the traveller's home location, the duration of residence, the supply of activity locations in the vicinity of home and the resulting neighbourhood travel

- Regular activities: Mobility to and from frequently visited activity locations such as shopping, work or school

- Travel between and around the pegs: Movements between the centres of daily life travel

Figure 1 Simplified activity space representation

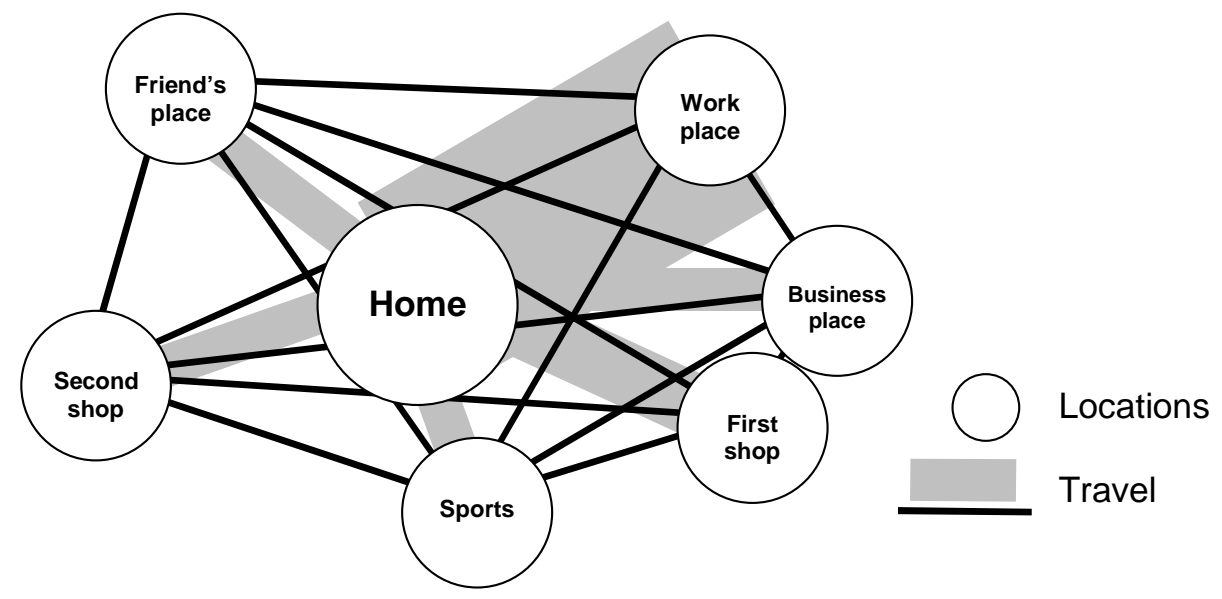

Adopted from Maier, Paesler, Ruppert and Schaffer (1977) 57

In activity spaces, travellers choose routes through time and space to meet their obligations, needs and desires. The travellers will try to choose these routes optimally, but they are constraint by their knowledge (mental map), their reasoning abilities and by the time and concentration they have available to construct and select a route.

The lack of earlier empirical research requires the development of suitable new measures to operationalise the activity space concept. Describing and comparing revealed spatial activity patterns of individuals over time is therefore a conceptual challenge. The indicators should on the one hand visualise spatial behaviour, and on the other hand provide a measure of the size of the activity space. The approaches presented here involve an increasing level of detail and comprehensiveness. 
The activity space consists of the locations which the person has visited, and the routes and areas the person has travelled through, in particular those locations which have been registered and seen, but not necessarily visited yet. The Mobidrive travel diary provides information about the locations visited, but not about the routes travelled. A GPS-based data set would be different here. It is possible to impute the route taken by making suitable behavioural assumptions. In the case of assuming time or distance shortest paths, one has to accept that in reality the traveller will have travelled longer because he deviated from the shortest path, searched for parking, made a mistake while walking from the parking space/bus stop to the final destination, etc..

Three measures will be used in the following (for details see below):

A two-dimensional confidence ellipse (interval) around a suitably chosen centre point. This measures only uses the information about the locations visited and by construction assumes that the person knows all of the area covered by the ellipse, which is generally rather large because of the assumed functional form (ellipse).

The activity space, as measured, by kernel densities, again uses information about the locations, but is more restrictive in its spatial assumptions. Here only those areas are included which have been visited with a certain non-zero likelihood.

The third approach is based on the idea of minimum spanning tree (network), i.e. the length of the minimum distance routes between the locations visited, or the area covered by a buffer around those routes.

\subsection{Confidence ellipses}

The first approach is the estimation of confidence ellipses to the spatial distribution of trip destinations. Confidence ellipses are analogous to the confidence interval of univariate distributions as the smallest possible (sub-)area in which the true value of the population should be found with a certain probability (e.g. 95\%). This measure can be shown to correlate with a range of simpler measures of travel behaviour, such as the standard distance ${ }^{3}$ (see e.g. Schönfelder, 2001; Schönfelder and Axhausen, 2001). The confidence ellipse picks up the methodological, activity space oriented work of the 1970s UMOT project (Unified Mechanism of Travel) and subsequent studies (Zahavi, 1979; Beckmann, Golob and Zahavi 1983a; 1983b), respectively similarly defined Jennrich-Turner home ranges long used in the biological habitat research to analyse competition and density effects of animals' space usage (see Jennrich and Turner, 1969; Southwood and Henderson, 2000).

\footnotetext{
${ }^{3}$ Standard distance: Square root of the distance between each activity location and their arithmetic mean (centre of gravity)
} 
The Mobidrive data allows the calculation of the confidence ellipses for each respondent based on the traveller's trips during the six-week reporting period. The calculations were performed using the common GIS software ESRI Arcview ${ }^{\circledR}$ (see Schwarze and Schönfelder, 2001 for the relevant ArcView extension).

The orientation of the ellipse is determined by the sign of the linear correlation coefficient between the coordinates $\mathrm{x}$ and $\mathrm{y}$ of the activity locations; the longer axis of the ellipse (if shown) is the regression line (Figure 2).

Figure 2 Example of a 95\% confidence ellipse with outlier

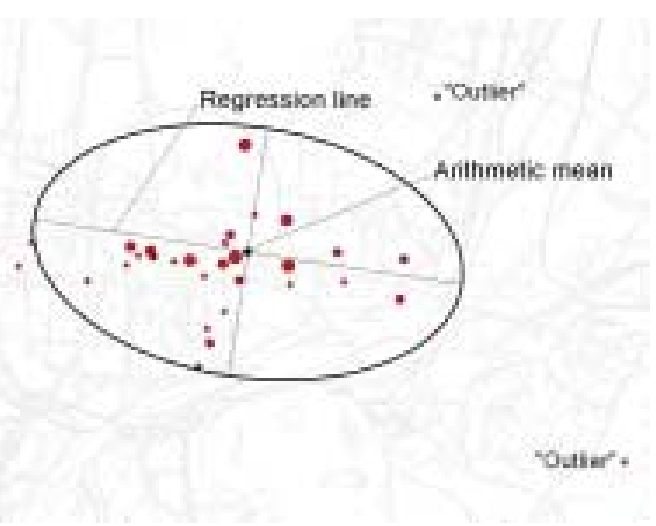

$$
\begin{aligned}
& s_{x y}=s_{y x}=\frac{1}{n-2} \sum_{i=1}^{n}\left(x_{i}-\bar{x}\right)\left(y_{i}-\bar{y}\right) \\
& S=\left(\begin{array}{c}
s_{x x} s_{x y} \\
s_{y x} s_{y y}
\end{array}\right)
\end{aligned}
$$

Ellipse size A:

$$
A=6 \pi|S|^{\frac{1}{2}}
$$

Dots show location and intensity of observed activity locations of one respondent

In the context of spatial behaviour, a confidence ellipse may be employed as description of the activity location distributions in space. Furthermore, the size of the area is an indicator for the dispersion of visited locations and may be used to compare the dispersion between travellers or of one respondent on different days of the week.

As a first solution, the arithmetic mean- either of the all unique coordinates or the coordinates weighted by the frequency of visit - may be accepted as the core of the activity space. It seems nevertheless necessary to modify this analytical geometrical concept to gain a behaviourally more realistic measure.

To reach this, one should consider two important characteristics of daily mobility: 1) the home location is the undoubted peg of daily mobility (see also Cullen and Godson, 1975) and 2) for most travellers it can be assumed that the geometric shape of the revealed activity patterns is ellipse-like with two focal points (see Dijst, 1999 for empirical findings). For the calculations based on weighted frequencies, the arithmetic mean is normally close to home though this location is not a relevant real-world address. For a modification of the base approach, these facts are taken into account by either substituting the arithmetic mean by the coordinate of the home location (alternatively any other important activity location visited) or even by two pegs as focal points. 
Figure 3 shows the results of such modifications. First, a) ellipses are shown where the home locations substitute the mean point in the calculation of the covariance matrix. This figure indicates significant differences between the chosen persons, but also on the intra-personal level by weekdays and weekend. This is evident for the size of the fields, the location of the activity spaces within the city and the main axes of the ellipses.

The second extension (b) is the creation of two ellipses covering the activity locations related to home (such as home-based grocery shopping) plus a further peg such as work. These ellipses may be merged to visualise and measure the spatial clustering of secondary activities such as grocery shopping around the pegs (see e.g. Holzapfel, 1980 for early findings on these patterns).

Clearly, these changes restrict the mathematical validity of the confidence ellipse, but it allows a more plausible description of the travellers' activity patterns.

Figure 3 Extensions of the confidence ellipse concept

Home substituted for arithmetic mean location

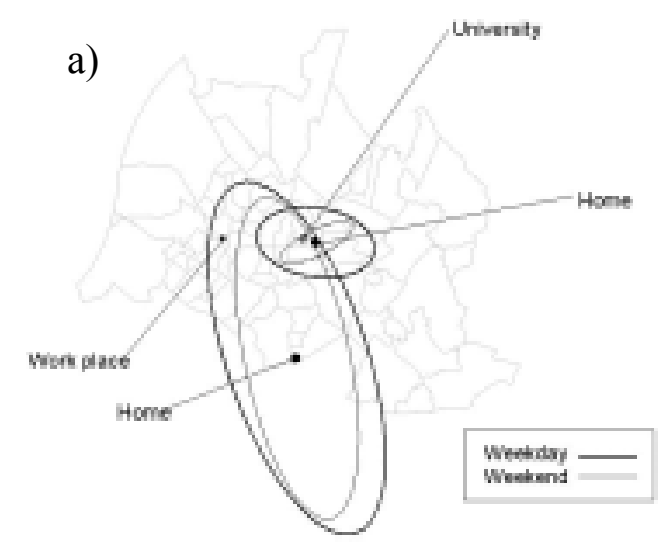

Merged main ellipses around home and work

b)

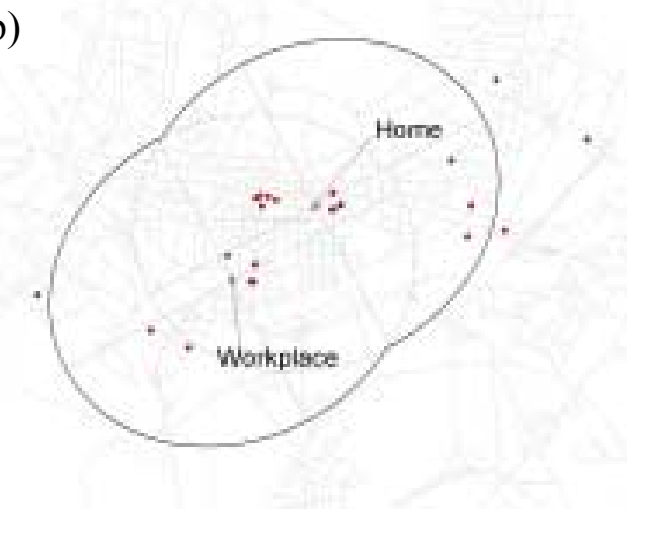

\subsection{Kernel densities}

In the second approach the activity space includes all areas for which there is a certain probability of or density of visit. These are estimated using a kernel density approach. The basic process behind the estimation of kernel densities is a transformation of a point pattern (such as the set of activity locations visited) into a continuous representation of density in a wider area. Generally spoken, the estimation is an interpolation or smoothing technique which generalises events or points to the area they are found in. The interpolation then leads to a calculation of a value for any point, cell or sub-region of the entire area which characterises the density. 
Kernel densities have been already applied successfully to large cross-sectional data sets (Kwan, 2000; Buliung, 2001). Modern GIS applications include tools to calculate such density measures effectively. ArcInfo was used in this study.

ArcInfo estimates densities within its integrated GRID module where raster grids are used to divide an area into a definable number of cells. Finally, the density values are assigned to the cells according to the kernel densities estimated for the underlying point pattern.

For the actual density estimation, a variety of approaches exist (for overviews see Silverman, 1986 or Fotheringham, Brunsdon and Charlton, 2000). Probably the most common approach is the fixed kernel method (also applied here). A symmetrical - variably distributed - kernel function is placed over each data point. For all locations in the entire area - not only for the data points - the overlapping values are summed which yields the density or intensity estimate (Figure 4). This automatically leads to a smoothing of the surface where the level of smoothness depends on the bandwidth of the kernel function which is analogous to the width of ordinary histogram boxes. The bandwidths may be varied according to the necessary degree of smoothness - with greater smoothing at bigger bandwidths or values of the smoothing parameter. The GIS finally may represent the resulting estimates for all grid cells as a continuous surface.

Considering a grid structure in which single points are substituted by grid cells, the base kernel density is given by:

$$
\lambda(s)=\sum_{d_{i}<\tau} K\left(\frac{d_{i}}{\tau}\right)
$$

with

$\lambda$ density estimate at grid point $s$

$\tau \quad$ bandwidth or smoothing parameter

$K \quad$ kernel function (to be further specified)

$d_{i} \quad$ distance between grid point $s$ and the observation of the $i$ th event 
Figure 4 Kernel density estimates

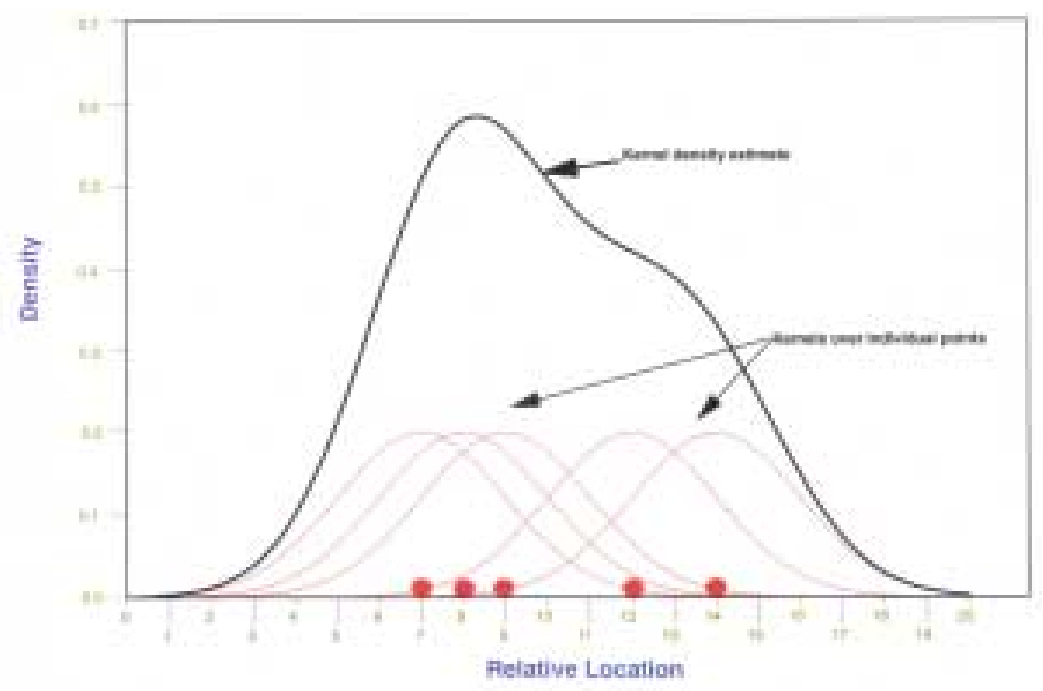

Source: adopted from Ned Levine and Associates (1999) 202

The kernel function $K$ itself may have different forms such as normal, triangular or quartic. The results do not differ significantly as long as the distribution is symmetrical. In the following, a quartic kernel function (see Mitchell, 1999 for details ) - is used which leads to the following kernel density

$$
\lambda(s)=\sum_{d_{i}<\tau} K\left\{\left[\frac{3}{\tau^{2} \pi}\right]\left[1-\frac{d_{i}^{2}}{\tau^{2}}\right]^{2}\right\}
$$

A particularity of the quartic function - e.g. compared to a normal distribution - is that outside the specified bandwidth $\tau$, the function is per definition set to zero - with implications for the behavioural model. This means that activity locations outside a specified radius do not contribute to the density estimation of the particular point (cell) in space. In other words, a quartic distribution of the kernel function adds weight to locations closer to the centre of the bandwidth than those further apart (see NedLevine and Associates, 1999 for characteristics of the different kernel forms).

Figure 6c shows the principle of the approach by visualising a kernel density grid around the workplace location of a Mobidrive Karlsruhe sub-sample respondent. The frequency of visit is considered as a (linear) weight.

It can be easily seen that - due to the quartic kernel function - the densities decrease with growing distance from the most frequently visited location(s). The size of the dots represent the num- 
ber of visits over the six-week reporting period. The visual effect of the GIS output, i.e. the graduation of colours or the visual smoothness, depends very much on the cell size chosen. Principally, the sum of the densities across all cells of the reference area is directly related to the grid cell size - this means that the quotient of the overall density divided by number of cells is the same for every setting. Consequently, a comparison of the activity spaces (size) of one person over time or between persons has to be based on the same cell size and bandwidth.

From a behavioural point of view, the selection of the bandwidth of the kernel function (search radius) is an important issue. For the activity location data it may be argued that the bandwidth reflects a maximum distance of spatial interaction between activity locations. One could raise the question which activity locations have a functional affiliation with each other in the understanding of people (e.g. home location and local groceries). In addition to that, what is the distance travellers accept to e.g. walk to the locations form home - indicating vicinity or familiarity with one's neighbourhood. Hence, the choice of the bandwidth should reflect our understanding of proximity and neighbourhood in daily travel. For the following example and for the calculations in the consequent chapter, a bandwidth of $1000 \mathrm{~m}$ was chosen which can be defined as the maximum walking distance which is accepted between two places $(75 \%$ percentile of the walking trip length distribution).

The size of the activity space can be measured as:

a) The number of cells for which the density exceeds a certain threshold (i.e. $>0$ )

b) measure a) reduced by areas probably not open for ordinary activities, such as heavy industrial or utility areas (see below).

Turning to measure (b), it can be argued that the spatial supply (distribution) of activity opportunities is a key factor for activity or trip demand and therefore for the shape of activity spaces. The availability of exact data covering the supply - such as digital point of interest data - is still limited and selective, though, which makes it difficult to use such an approach. Nevertheless, aggregate land use data, which is available for both Mobidrive case study cities, at least yields information on areas of minimal interest for private travel such as agricultural land, industrial areas etc. One could introduce such areas of no interest to tailor the area to a more likely shape (Figure $6 \mathrm{~b}, \mathrm{~d}$ and $\mathrm{f}$ ). Undoubtedly, this is connected with a further uncertainty about the actual usage of urban space as it remains unclear if the definition of the potential exclusion areas varies for the different respondents. Nevertheless, the proposed approach is a further methodological refinement worth considering. 


\subsection{Minimum spanning trees (network)}

The activity space measures presented above assume that travellers have a spatially continuous knowledge or even make use of a continuous urban space around the activity locations visited. This is a simplification of human behaviour as the identified areas are certainly not used in a literal way. Furthermore, the potential knowledge of activity locations or landmarks is probably overestimated - depending on the chosen bandwidth of the kernel function.

A refined measure should acknowledge that transport network structures shape the traveller's perception of potential activity locations as well as the knowledge of place and the spatial orientation (Golledge, 1999). Hence, calculating the size as well as visualising the shape of human activity spaces should be oriented towards the paths chosen by the traveller.

One possibility is to identify the part of the network which is actually used by the travellers. This particular portion and the roads' adjacent built environment can be assumed to be known to the traveller with the level of knowledge dependent on the frequency of usage. The identification of the network links needs to rely initially on assumptions about the chosen routes, as the Mobidrive survey design did not capture the paths chosen. As an approximation of the actual path, the distance shortest route for each unique relation reported by the Mobidrive respondents was calculated - based on the individual 6-week origin-destination matrix and available road network ${ }^{4}$ employing the ArcInfo NETWORK module. Enhancements of this procedure are imaginable, e.g. by substituting the deterministic shortest path algorithm by a probabilistic one (see Sheffi, 1985; Bovy, 1996). Furthermore, the trips could be properly assigned to the different modal networks according to the modes actually chosen.

The initial application of the concept is leading to a geometry which can be compared to a minimum spanning tree (Figure 5) - well known from the graph theory. The minimum spanning tree consists of the set of links, which connect a location to a desired set of destinations having the minimum total length. Due to non-home based trips, this tree will be transformed into a network of growing complexity depending on the frequency and starting points of such trips. The structure and size of the tree is a further quantitative indicator for the perception, knowledge and especially the usage of urban space. Considering the perception of the (built) environment, it can be assumed that there is considerable correlation between the frequency of using a network link and the knowledge of the surrounding area. It is widely agreed by psychologists and geographers that travelling through an environment is the common way of spatial learning and acquiring spatial expertise (Golledge, 1999).

\footnotetext{
${ }^{4}$ A digitalised road network was only available for the City of Karlsruhe.
} 
What can be especially seen from the first of the two examples in Figure 5 is that again the home location is the major hub for daily life travel acting as a central node in the tree. This is what could be expected as the share of complex trip chains with diffuse travel relations is much smaller than the amount of simple home-based trips, such as home-work-home, home-shop-home or home-leisure-home. More than $70 \%$ of all Mobidrive home based activity chains (i.e. tours or journeys) involve only one out-of-home activity.

The concept can be extended from a measure of the total length of the tree to an areal measure by buffering around the links of tree (See (Figure 6f).

Figure 6 provides in conclusion a comparison of those measures for one randomly chosen individual. It shows the activity spaces of a female student based on the local ${ }^{5}$ trips she reported. It can be seen - especially from the activity density and the spanning tree visualisation - that the activity locations are clustered around two the main daily life centres home and university.

Figure 5 Two examples of minimum spanning trees (networks)

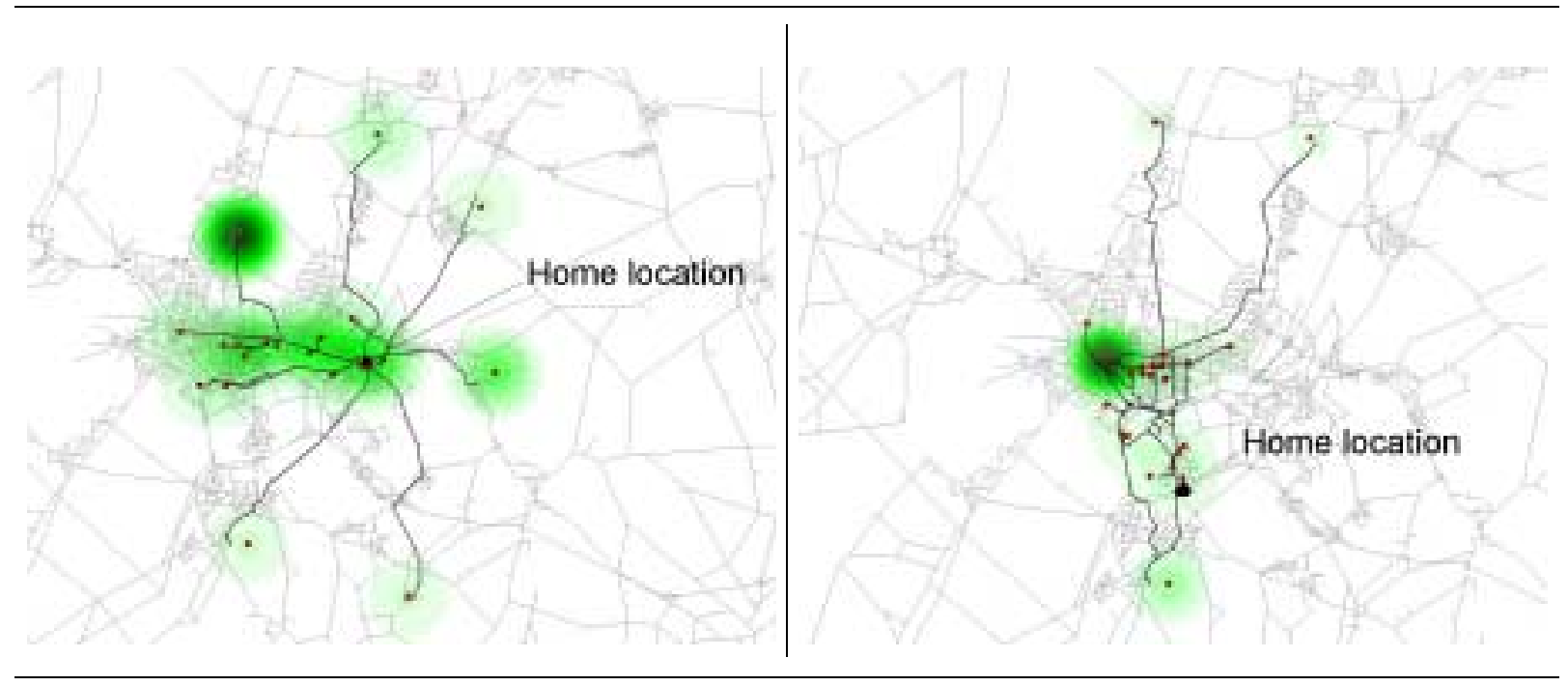

\section{Trips, locations and activity spaces}

Before focussing on the respondents at risk of social exclusion due to their age, income or car access, it is necessary to discuss the interactions between activity levels, the number of unique locations visited and the size of the activity space measured. Frequently, the number of trips is used as a measure of social involvement, in particular trips to work/education and for social/leisure purposes. Still, number can only function as this proxy if the number of locations and the size of

\footnotetext{
${ }^{5}$ Only trips within a distance of appr. $25 \mathrm{~km}$ form the city centre are considered.
} 
the activity space grows with it. Many trips to one or few locations, even if widely spread would indicate rather the opposite of social inclusion.

The ratio of trips to unique locations was previously unknowable, as the normal short duration surveys cannot provide a credible estimate of this parameter. The Mobdrive data permit, within the limits of geocoding accuracy discussed above, a first impression of this aspect of spatial choice behaviour. If the number of unique locations grows consistently with the number of trips, then variety seeking, for its own sake, becomes a credible explanation of these choices. Figure 7 shows this pattern indicating that the respondents add about one new - i.e. not yet visited location - for about every five trips. This pattern of on-going addition to the list of locations is confirmed by Figure 8 showing the average number of locations visited on any day and the share of those, which had not been visited before. Even after six weeks the respondents continue to add further locations. 
Figure 6 Measurement approaches compared

a) $95 \%$ confidence ellipses (Area weekdays = $11.04 \mathrm{~km}^{2}$, weekends $\left.=2.61 \mathrm{~km}^{2}\right)^{*}$

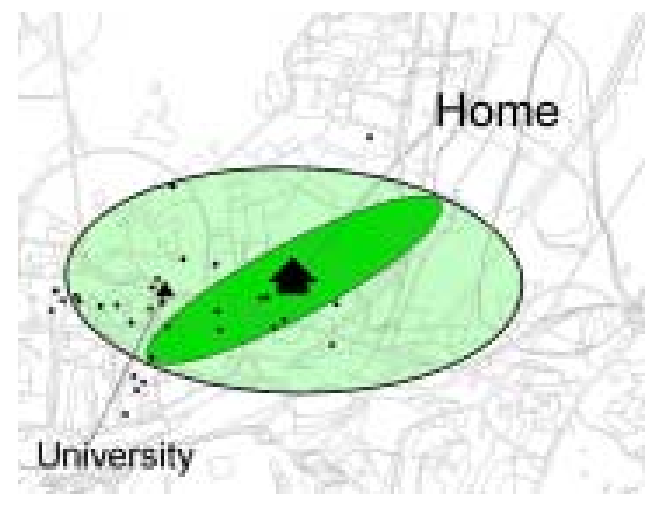

c) Area with a positive activity density (Area $=11.25 \mathrm{~km}^{2}$ )

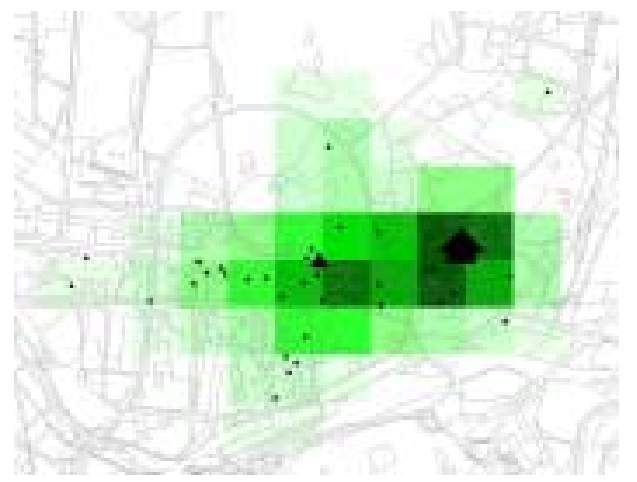

${ }^{*}$ Locations weighed by frequency of visit, cell size: $500 \mathrm{~m}$, search radius: $1000 \mathrm{~m}$

e) Minimum spanning network; buffer width $=200 \mathrm{~m}\left(\right.$ Area $\left.=10.28 \mathrm{~km}^{2}\right)$

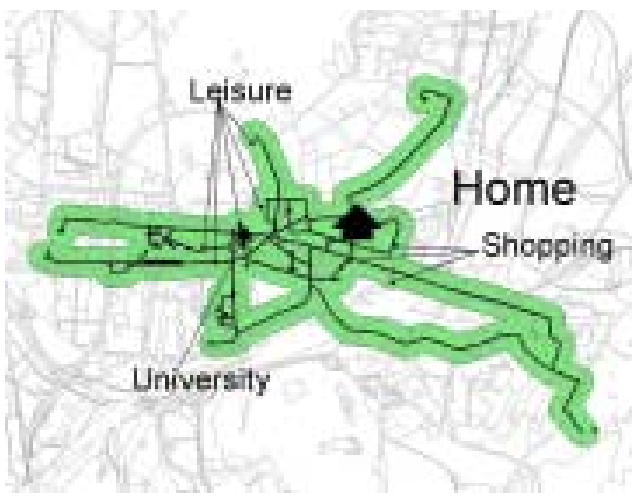

b) $95 \%$ confidence ellipse corrected (Area weekdays $=10.1 \mathrm{~km}^{2}$, weekends $\left.=2.47 \mathrm{~km}^{2}\right)^{*}$

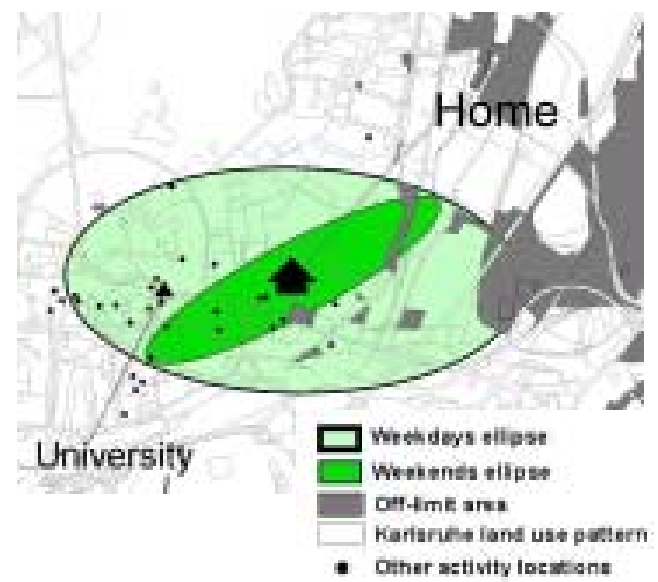

d) Area with a positive activity density corrected $\left(\right.$ Area $\left.=11.16 \mathrm{~km}^{2}\right)$

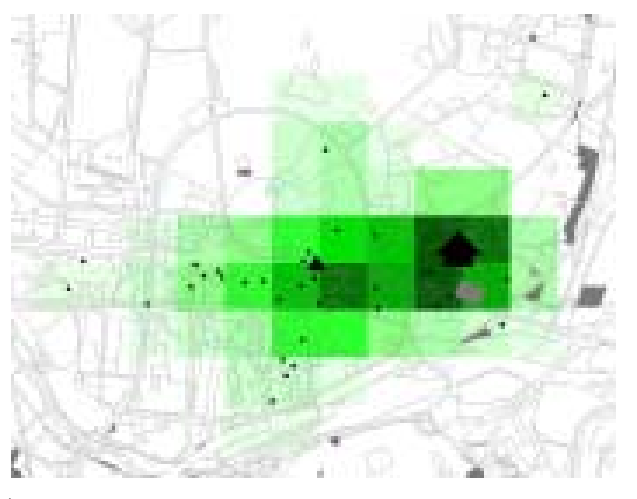

* Locations weighed by frequency of visit, cell size: $500 \mathrm{~m}$, search radius: $1000 \mathrm{~m}$

f) Minimum spanning network; buffer width $=200 \mathrm{~m}$; corrected $\left(\right.$ Area $\left.=10.20 \mathrm{~km}^{2}\right)$

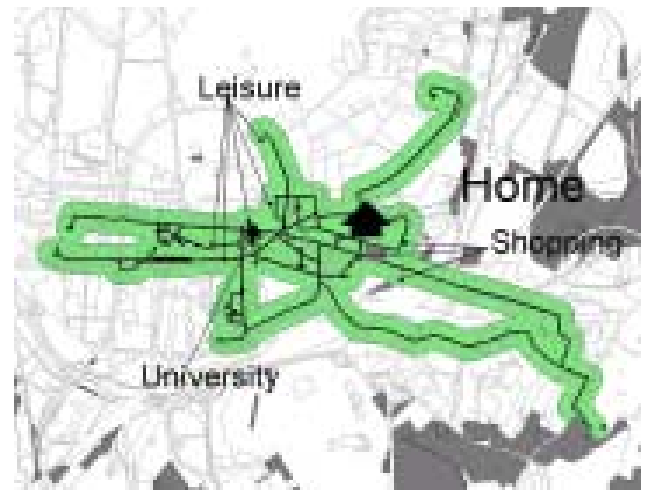

The original question was, if the number of trips is a good proxy for the size of the activity space. Figure 9 relates three measures of the size of the activity space to the number of trips and the number of unique locations. All of these concern only trips and locations within the study areas 
(see above). Trips to destinations further away are excluded here. The strength of the link between the number of trips and the number of unique locations and the size of the activity space differs between the measures. The size of the $95 \%$ confidence ellipse is unrelated to either measure, but the other two are quite tightly related. In the case of the length of the minimum spanning networks the relation seems to be non-linear. The link between the number of unique locations and the size of the activity space is stronger as measured by simple linear regression.

This initial analysis has highlighted the variety seeking behaviour of the respondents, who continue to reveal not yet visited locations throughout the six-week reporting period. They combine this with an activity space which increases with the number of trips and the number of unique locations visited. This is a second aspect of the underlying variety seeking preference.

Figure 7 Number of trips and number of unique locations visited

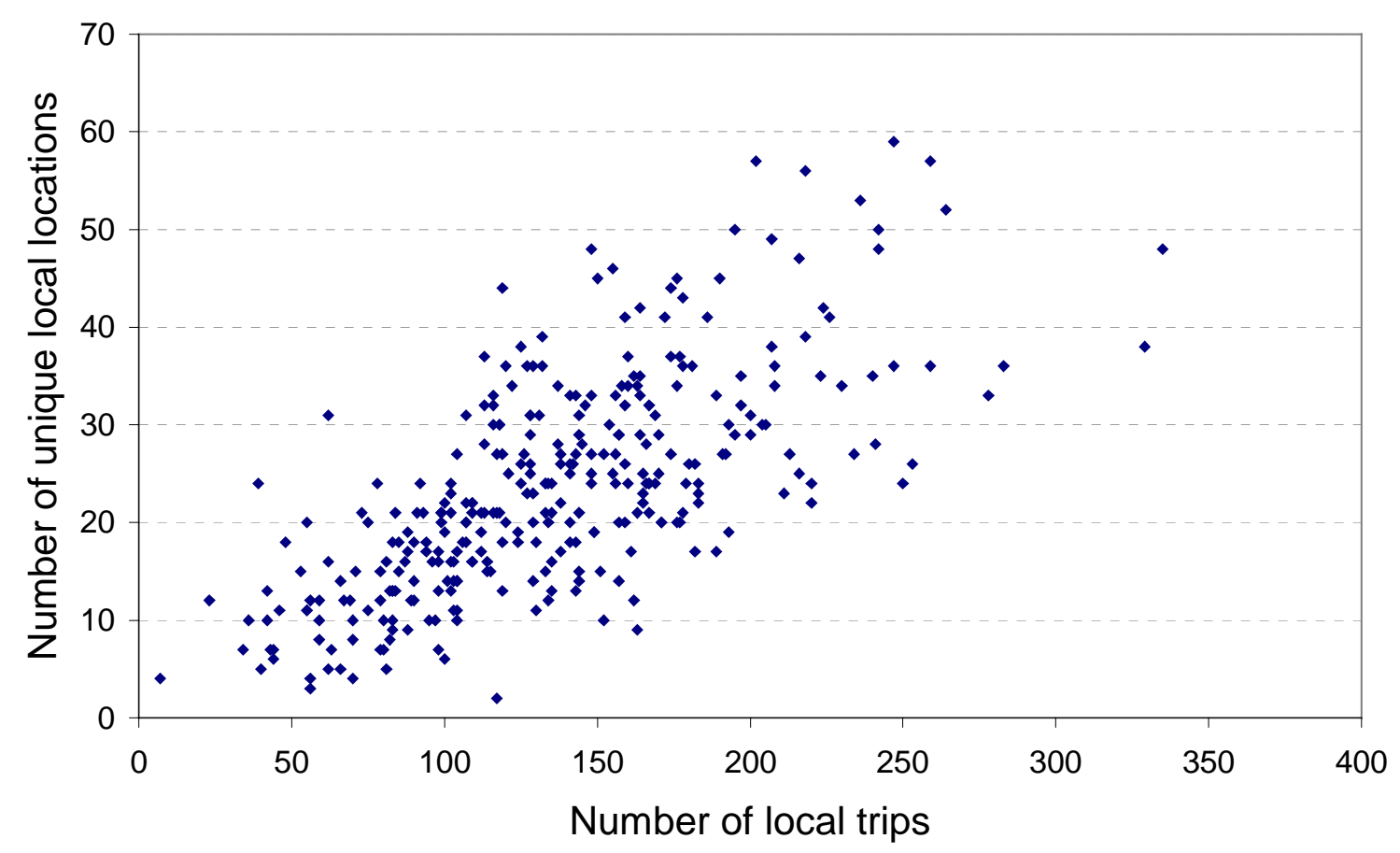


Figure 8 Share of previously not visited locations by day of survey

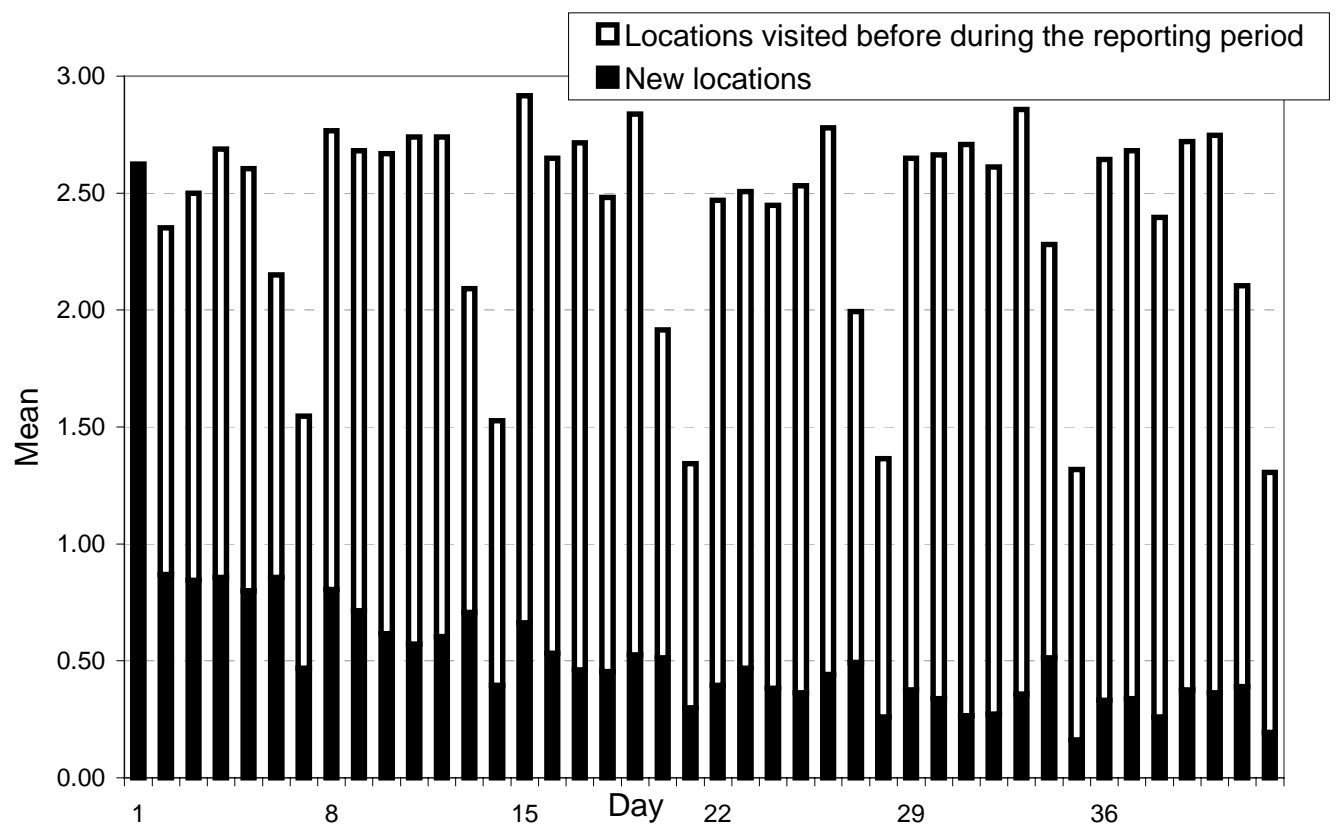


Figure 9 Size of activity space versus number of trips or number of unique locations visited $95 \%$ confidence ellipse (locations weighted by number of trips) (Karlsruhe and Halle; local trips only) $\left[\mathrm{km}^{2}\right]$
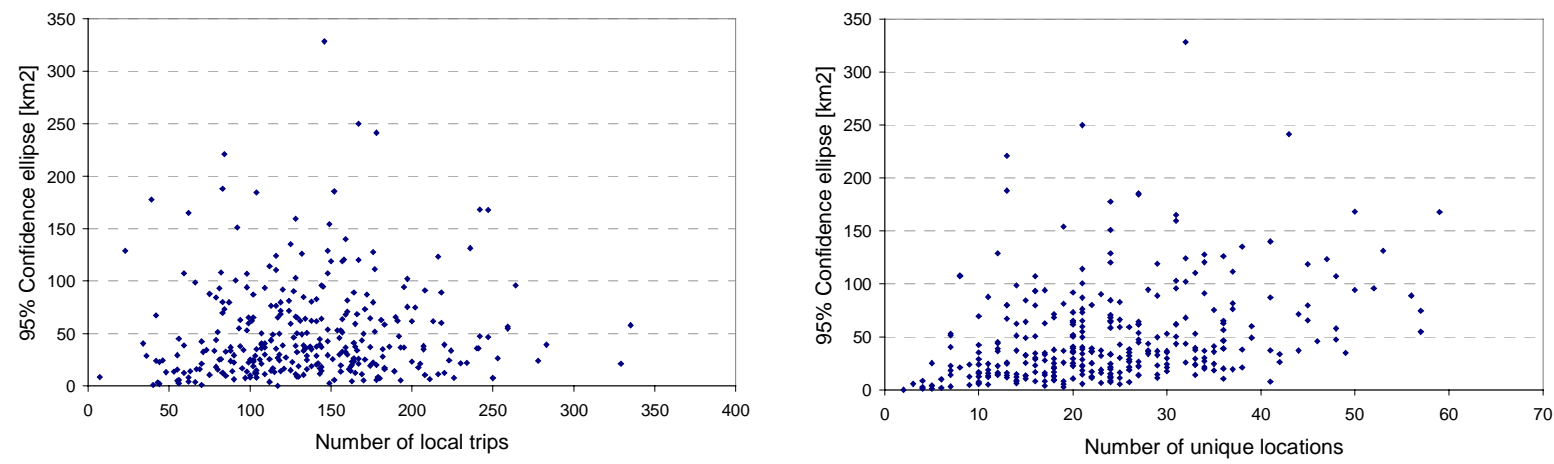

Area with positive kernel density (locations not weighted by number of trips) (Karlsruhe and Halle; local trips only) $\left[\mathrm{km}^{2}\right]$
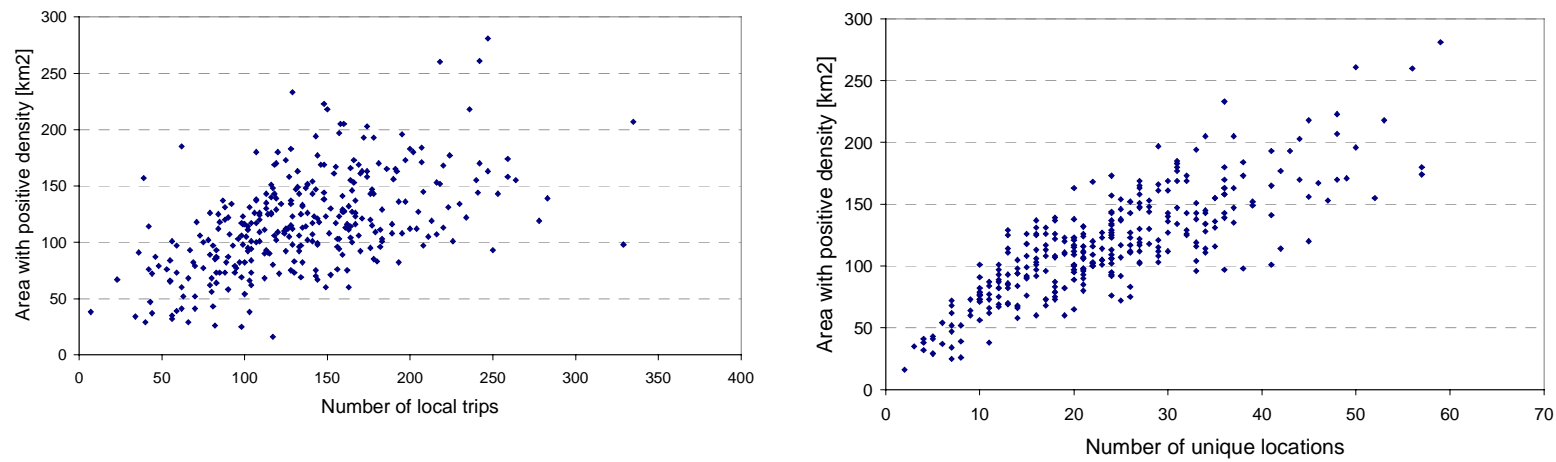

Length of minimum spanning networks (weighted by number of trips) (Karlsruhe; local trips only) $[\mathrm{km}]$
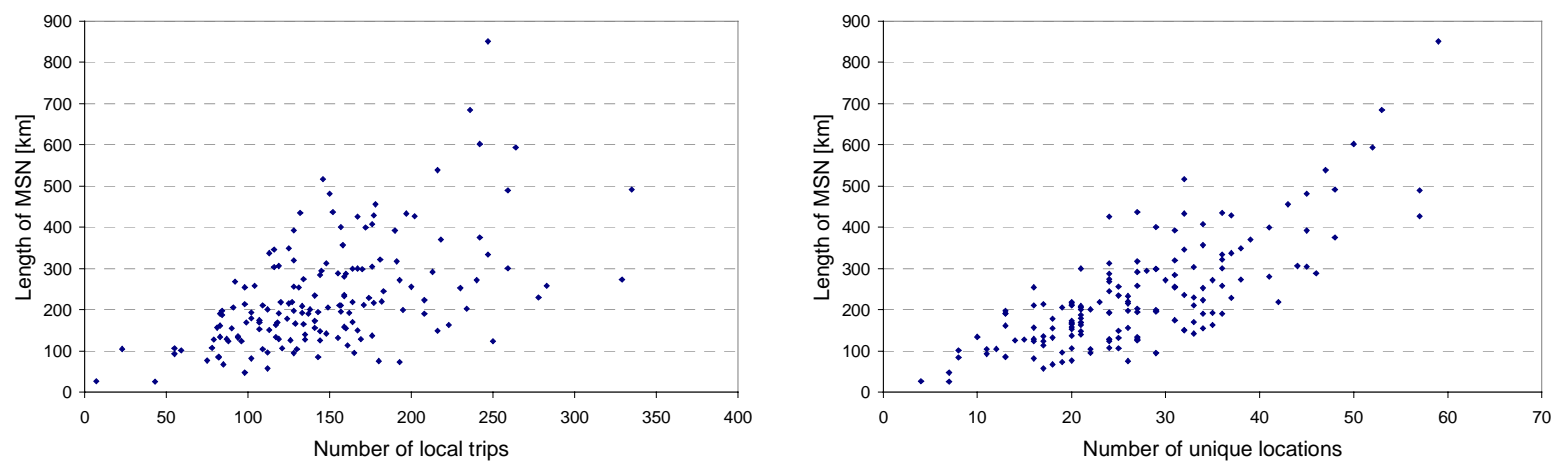


\section{Activity space and social indicators}

As mentioned above, the Mobidrive study did not focus on social exclusion which means that neither the sampling strategy nor the survey content focused on this issue. Still, the sample contains a wide range of respondents in terms of income, home location within the urban area and ownership of mobility tools (vehicles and public transport season tickets). Table 2 summarises these differences for the two cities and two selected measures of activity spaces size (the area with a positive kernel activity density estimate [in 500*500 meter grid units] and length of minimum spanning network $[\mathrm{km}]$ weighted by the number of journeys). The minimum spanning network measure is only available for Karlsruhe, due to the lack of a geocoded road network for Halle. These two were chosen to represent the different approaches (See Table 1 for the correlation structure between the measures).

The significant differences vary according to measure, as these stress different elements of the observed behaviour. For the kernel density measure significant differences are detectable for parttime workers and those, who are the main user of a car. For the minimum spanning network measure some income groups and some age groups are different.

Table 1 Pearson correlation coefficients between the size measures (Karlsruhe)

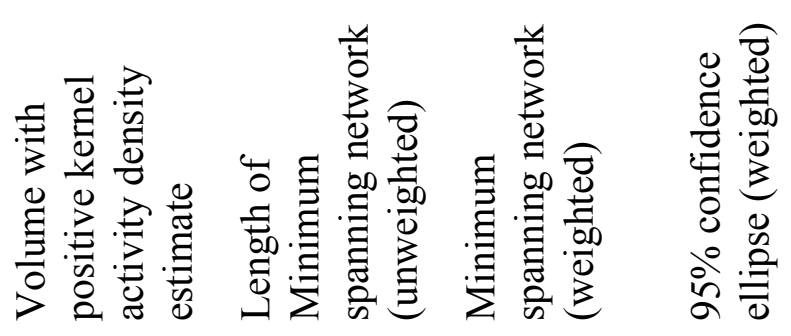

Area with positive kernel activity .496

.775

.808

.394 density estimate (unweighted)

Volume with positive kernel activity .394 .504 density estimate (unweighted)

Minimum spanning network .928 .652 (unweighted)

Minimum spanning network .594 (weighted by number of journeys)

All correlations shown are significant at the 0.01 level (2-tailed). 
Table 2 Average size of activity space by socio-demographic characteristics

\begin{tabular}{|c|c|c|c|c|}
\hline & \multicolumn{2}{|l|}{ City } & \multirow[t]{2}{*}{ Both cities } & \multirow[t]{2}{*}{ Karlsruhe } \\
\hline & \multicolumn{2}{|l|}{ Karlsruhe } & & \\
\hline & $\begin{array}{l}\text { Area with } \\
\text { positive kernel } \\
\text { density } \\
\text { estimate } \\
\text { (unweighted) }\end{array}$ & $\begin{array}{l}\text { Area with } \\
\text { positive kernel } \\
\text { density } \\
\text { estimate } \\
\text { (unweighted) }\end{array}$ & $\begin{array}{l}\text { Area with } \\
\text { positive kernel } \\
\text { density } \\
\text { estimate } \\
\text { (unweighted) }\end{array}$ & $\begin{array}{l}\text { Length of } \\
\text { minimum } \\
\text { spanning network } \\
\text { (weighted) }\end{array}$ \\
\hline & \multicolumn{3}{|c|}{ [Number of $500 * 500 \mathrm{~m}$ grid units] } & {$[\mathrm{km}]$} \\
\hline \multicolumn{5}{|l|}{ Sex } \\
\hline Female & 129 & 107 & 118 & 237 \\
\hline Male & 120 & 112 & 116 & 227 \\
\hline \multicolumn{5}{|l|}{ Income per adjusted head } \\
\hline Up to $2000 \mathrm{DM}$ & 113 & 110 & 111 & 208 \\
\hline 2 to $3000 \mathrm{DM}$ & 134 & 104 & 119 & 236 \\
\hline 3 to $4000 \mathrm{DM}$ & 117 & 133 & 122 & 218 \\
\hline $4000 \mathrm{DM}$ and more & 127 & 113 & 122 & 274 \\
\hline \multicolumn{5}{|l|}{ Main car user } \\
\hline No & 116 & 105 & 110 & 204 \\
\hline Yes & 135 & 117 & 127 & 268 \\
\hline \multicolumn{5}{|l|}{ Season ticket local PT } \\
\hline No & 127 & 111 & 118 & 242 \\
\hline Yes & 121 & 104 & 114 & 214 \\
\hline \multicolumn{5}{|l|}{ Working hours } \\
\hline Up to $10 \mathrm{~h} /$ week & 116 & 103 & 109 & 192 \\
\hline 10 to $35 \mathrm{~h} /$ week & 138 & 149 & 141 & 279 \\
\hline 35 and more $\mathrm{h} /$ week & 129 & 111 & 120 & 260 \\
\hline \multicolumn{5}{|l|}{ Age } \\
\hline Up to 17 years & 118 & 87 & 102 & 206 \\
\hline 18 to 29 Years & 110 & 130 & 120 & 212 \\
\hline 30 to 44 years & 141 & 112 & 126 & 283 \\
\hline 45 to 59 years & 128 & 115 & 122 & 252 \\
\hline 60 years and older & 113 & 106 & 110 & 171 \\
\hline
\end{tabular}

Excluding respondents with less than 40 trips over the six-week reporting period 
Still, there is no pattern recognisable that the person groups normally associated with social exclusion (the female, the old, those with low incomes) are significantly different from the rest of sample.

This impression is confirmed by multivariate analysis of the data using a generalised linear model. The variables had the same grouping as in Table 2. Three variables were tested in addition: distance between city centre (1.5 kilometre classes) and home location, number of reported local trips and the observed number of unique local destinations.

Table 3 Summary of the GLM results by city, measure and model: significance levels (Excluding persons with less then forty reported trips; observations with missing values are also excluded)

Variable

Length of minimum Area with positive kernel density estimate spanning network (unweighted) (weighted)

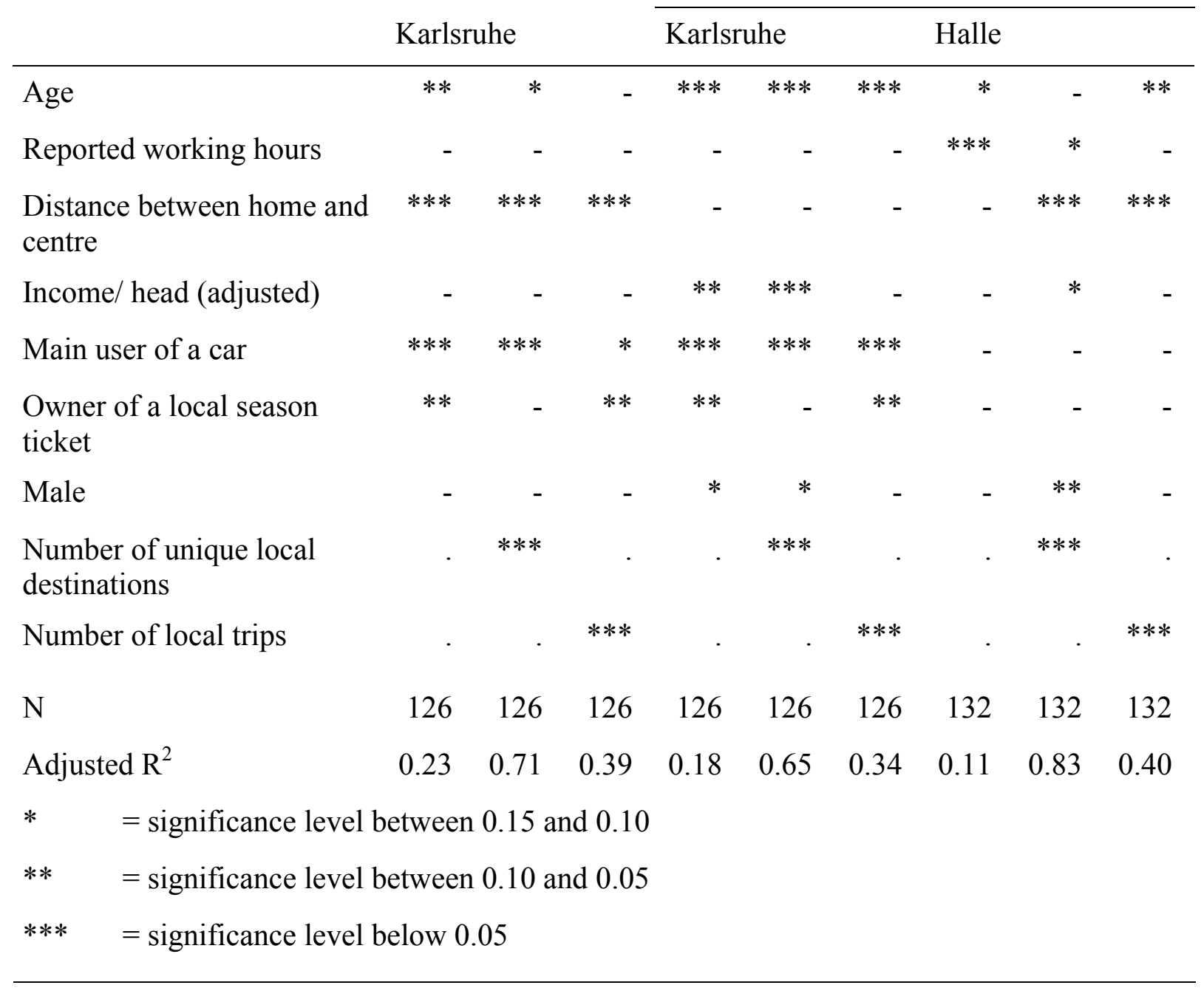


The pattern of the results is interesting, but not stable. In particular, the covariates (number of unique local destinations and number of trips) pick up different aspects of the data. In Karlsruhe, car access and season ticket ownership is consistently significant, while working hours and sex are not. Income, destination between home and city centre and age vary. In the minimum spanning network measure, which emphasises the spatial spread, the distance to the centre is consistently significant, but not in the other measure, where the densities can define separate islands.

In Halle, working hours and destination between home and the city centre are the most prominent variables. Still, none is consistently significant. The lack of significance of car access and season ticket ownership is surprising given their impact in Karlsruhe.

The models, which use only the socio-demographic variables, have a poor fit in all three cases. While the addition of the number of trips variable improves the model fit, only the models including the number of unique local destinations convince in a statistical sense. Due to the spatial variety seeking already discussed above this variable is able to describe the spatial reach of the respondents. Now, that this spatial variety seeking can be accepted as an assumption, the inclusion of the number of unique local destinations becomes nearly tautological.

The GLM combines an analysis of variance type approach for the categorical variables with a regression type analysis of continuous variables. The significance levels reported above imply that one or more of the categories of a variable are significantly different from the survey samples. The exact categories can vary from model to model without describing trends. A consistent patterns is visible for the variable distance from the city centre, where the activity spaces increase up to the $4.5 \mathrm{~km}$ band, where they stabilise.

The reverse analysis confirms this impression. For Table 4 the respondents were grouped into four classes, each representing a quarter of the distribution in each city. The quartiles were defined with respect to the distribution of the activity spaces as measured by the areas with positive densities. For each class the average value or share of the most important variables was calculated. There are some significant differences, but none concerning variables associated with social exclusion (income, age, sex). There are more parents in the highest quartile, respondents in the lower half of the distribution report fewer working hours than those in the highest quartile; they have equally fewer driving licences; those in the lowest quartile are also in comparison with the highest quartile less likely to be the main users of a car. 
Table 4 Socio-demographic profiles of the respondents by quartiles of the activity size distribution (areas with positive kernel density estimates)

\begin{tabular}{|c|c|c|c|c|c|}
\hline \multirow[t]{2}{*}{ Variables } & \multirow[t]{2}{*}{ Statistic } & \multicolumn{4}{|l|}{ Class } \\
\hline & & $\begin{array}{l}\text { Up to } \\
\text { 1. Quartile }\end{array}$ & $\begin{array}{l}\text { 1. Quartile } \\
\text { - Median }\end{array}$ & $\begin{array}{l}\text { Median - } \\
\text { 3. Quartile }\end{array}$ & $\begin{array}{l}\text { Above } \\
\text { 3. Quartile }\end{array}$ \\
\hline \multirow[t]{2}{*}{ Male } & Share & 48.1 & 52.5 & 56.1 & 41.9 \\
\hline & Standard Error & 5.6 & 5.6 & 5.5 & 5.8 \\
\hline \multirow[t]{2}{*}{ Age } & Mean & 39.062 & 39.525 & 39.110 & 42.770 \\
\hline & Standard Error of Mean & 2.306 & 2.329 & 2.102 & 1.617 \\
\hline \multirow[t]{2}{*}{ Parent } & Share & 22.2 & 28.8 & 29.3 & 51.4 \\
\hline & Standard Error & 4.6 & 5.1 & 5.1 & 5.8 \\
\hline \multirow{2}{*}{$\begin{array}{l}\text { Number of } \\
\text { working hours }\end{array}$} & Mean & 16.315 & 17.079 & 17.805 & 23.779 \\
\hline & Standard Error of Mean & 2.341 & 2.281 & 2.334 & 2.541 \\
\hline \multirow[t]{2}{*}{ Drivers licence } & Share & 53.1 & 63.8 & 70.7 & 81.1 \\
\hline & Standard Error & 5.6 & 5.4 & 5.1 & 4.6 \\
\hline \multirow[t]{2}{*}{ Main user of a car } & Share & 28.4 & 40.0 & 43.9 & 51.4 \\
\hline & Standard Error & 5.0 & 5.5 & 5.5 & 5.8 \\
\hline \multirow[t]{2}{*}{ Household income } & Mean $[\mathrm{DM}]$ & 4242 & 4804 & 4160 & 4377 \\
\hline & Standard Error of Mean & 255 & 247 & 226 & 229 \\
\hline
\end{tabular}

\section{Conclusions and outlook}

The paper has introduced a number of new approaches to measure the size of human activity spaces: starting with a measure transferred from biology, but then suggesting further approaches. These measure have become possible for the first time, as only now data sets have become available for humans which are rich enough to allow this estimation at the personal level. The first measure, the confidence ellipse overgeneralises the spatial patterns through its rigid geometric assumptions: the size estimated is therefore too high. The kernel density derived measures focus on the vicinity of the various locations to each other, but ignore their spread across the landscape. They permit isolated islands of activity, thereby ignoring the connections between those. The minimum spanning networks stress, on the other hand, the spatial spread of the activities in the study area by measuring the length of the routes between the locations. Figure 6 e and $\mathrm{f}$ presented an extension, which could be a reasonable compromise: the combination of the minimum span- 
ning networks with a spatial buffer. The quality of this compromise will need to be tested in future work.

The analysis of the Mobidrive sample revealed systematic differences between different categories of certain variables, but did not reveal clear classes of travellers with unusually small activity spaces. The analysis suggests that variety seeking is driving the respondents to seek out an ongoing stream of new (never yet observed) locations. Even at the end of the six week observation period about $20 \%$ of the locations had not been previously visited by the respondents. These locations are not clustered, therefore help to increase the size of the activity space (see Figure 9). Clearly, it is not known, if the locations were new to the travellers as this was not asked during the survey. Still, that does not change the interpretation that variety seeking is a crucial motivation for the respondents.

For this sample the proposed measures could not by used to identify a systematic disadvantage for the female, or older or lower income respondents. The overall level of trip making and therefore the number of unique locations visited dominated this aspect of traveller behaviour. It is well known, that the number of trips can only be partially explained by socio-demographic variables.

Clearly, this study and this sample was not designed to address this issue in the first place, as mentioned above. So, a dedicated attempt to construct a sample with respondents, which can be considered to be at risk, might lead to different conclusions. Given the wide variety in trip making the sample would need to be of sufficient size to allow firm conclusions. It would also need to be spread across different location types to avoid the compounding the possible effects of social exclusions with the effects of particular locations. In addition, it would be necessary to complement this study of current behaviour with a life history approach to place it in a wider biographical context, which can be assumed to be a powerful explanatory, as biography defines the expectations of the travellers in terms of the boundaries they are allowed to reach and cross.

\section{References}

Axhausen, K.W. (1998) Can we ever obtain the data we would like to have ?, in T. Gärling, T. Laitila and K. Westin (eds.) Theoretical Foundations of Travel Choice Modelling, 305-323, Elsevier, Oxford.

Axhausen, K.W. (2002) A dynamic understanding of travel demand: A sketch, Arbeitsberichte Verkehr- und Raumplanung, 119, IVT, ETH, Zürich. 
Axhausen K.W., A. Zimmermann, S. Schönfelder, G. Rindsfüser and T. Haupt (2002), Observing the rhythms of daily life: A six-week travel diary, Transportation, 29(2) 95-124.

Beckmann, M.J., T.F. Golob und Y. Zahavi (1983a) Travel probability fields and urban spatial structure: 1. Theory, Environment and Planning A, 15, 593-606.

Beckmann, M.J., T.F. Golob und Y. Zahavi (1983b) Travel probability fields and urban spatial structure: 2. Empirical tests, Environment and Planning A, 15, 727-738.

Bovy, P.H.L. (1996) Stochastic traffic assignment technique enhancements for congested networks, Modellen voor Overmorgen, 101-116.

Brandl, P. and K.W. Axhausen (1999) Karlsruhe 1975-1995: a case study of LRT development, Transportation Research Record, 1623, 155-164.

Brown, L.A. and E.G. Moore (1970) The intra-urban migration process: a perspective, Geografiska Annaler, 52(B) 1-13.

Buliung, R.N. (2001) Spatiotemporal Patterns of Employment and Non-Work Activities in Portland, Oregon, ESRI International User Conference, San Diego, California, July, 2001.

Church, A., M. Frost and K. Sullivan (2001) Transport and social exclusion in London, Transport Policy, 7 (3) 195-205.

Cullen, I. and V. Godson (1975). Urban Networks: The Structure of Activity Patterns. Progress in Planning, 4(1), 1-96.

DETR (2000) Social exclusion and the provision and availability of public transport, Department of Transport and the Regions, London.

Dijst, M. (1999) Two-earner families and their action spaces: A case study of two dutch communities, GeoJournal, 4(3) 195-206.

Downs, R. and D. Stea (1977) Maps in Mind - Reflections on Cognitive Mapping, Harper \& Row, New York.

Dürr, H. (1979) Planungsbezogene Aktionsraumforschung - Theoretische Aspekte und eine Pilotstudie, Beiträge der Akademie für Raumforschung und Landesplanung, 34, Hannover.

Fotheringham, A.S., C. Brunsdon und M. Charlton (2000) Quantitative Geography, Sage, London.

Gibb, K., A. Kearns, M. Keoghan, D. MacKay and I. Turok (1995) Revising the Scottish area deprivation index, I, Central Research Unit, Scottish Office, Edinburgh.

Goldenberg, J., B. Libai and E. Muller (2001) Talk of the network: A complex systems look at the underlying process of word-of-mouth, Marketing Letters, 12(3) 209-221.

Golledge, R.G. (1999) Human wayfinding and cognitive Maps, in R.G. Golledge (Ed.) Wayfinding Behavior, 5-45, The Johns Hopkings University Press, Baltimore/London. 
Golledge, R.G. and R.J. Stimson (1997) Spatial Behavior, The Guilford Press, New York and London.

Granovetter, M. (1973) The strength of weak ties, American Journal of Sociology, 78, 13601380 .

Grieco, M., J. Turner and J. Hine (2000) Transport, employment and social exclusion, Local Work, 26.

Hägerstrand, T. (1970) What about people in regional science?, Papers of the Regional Science Association, 24 (1) 7-21.

Hine, J. and F. Mitchell (2002) Transport Disadvantage and Social Exclusion: Exclusionary Mechanisms in Transport in Urban Scotland, Ashgate, Aldershot.

Holzapfel, H. (1980) Verkehrsbeziehungen in Städten, Schriftenreihe des Instituts für Verkehrsplanung und Verkehrswegebau, 5, Technische Universität, Berlin.

Horton, F. und D.R. Reynolds (1971) Effects of Urban Spatial Structure on Individual Behaviour, Economic Geography, 47, 36-48.

Jennrich, R.I. und F.B. Turner (1969) Measurement of non-circular home range, Journal of Theoretical Biology, 22, 227-237.

Kutter, E. (1973) Aktionsbereiche des Stadtbewohners: Untersuchungen zur Bedeutung der territorialen Komponente im Tagesablauf der städtischen Bevölkerung, Archiv für Kommunalwissenschaften, 13, 69-85.

Kwan, M.-P. (2000) Interactive geovizualization of activity-travel patterns using threedimensional geographical information systems: A methodological exploration with a large data set, Transportation Research C, 8(2), 185-203.

Lenntorp, B. (1976) Paths in space-time environment: a time geographic study of possibilities of individuals, Lund Studies in Geography, Ser. B. Human Geography, 44, Department of Geography, The Royal University, Lund.

Lynch D. (1960) The Image of the City, MIT-Press, Cambridge.

Maier, J., R. Paesler, K. Ruppert and F. Schaffer (1977) Sozialgeographie, Westermann, Braunschweig.

Marble, D.F., P.O. Hanson and S. Hanson (1972) Field Operations and Questionnaires, Household Travel Behavior, Study 1, Department of Human Geography, State University of New York at Buffalo, Buffalo.

Mitchell, A. (1999) The ESRI Guide to GIS Analysis, Volume 1: Geographic Patterns \& Relationships, ESRI Press, Redlands.

Ned Levine and Associates (1999) CrimeStat (Version 1.0): A spatial statistics program for the analysis of crime incidents locations, The National Institute of Justice, Washington. 
Scheiner, J. (2001) Berlin - noch immer geteilt? Untersuchungen zur Mobilität zwischen dem West- und Ostteil der deutschen Hauptstadt, Geographische Rundschau, 53(3), 17-23.

Schönfelder, S. (2001) Some notes on space, location and travel behaviour, Paper presented at the $1^{\text {st }}$ Swiss Transport Reseach Conference, Monte Verita, March 2001.

Schönfelder, S. and K.W. Axhausen (2001) Mobidrive - Längsschnitterhebungen zum individuellen Verkehrsverhalten: Perspektiven für raum-zeitliche Analysen, in M. Schrenk (Ed.) Tagungsband / Proceedings CORP 2001, Band 2, 315-321, Technische Universität, Wien.

Schönfelder, S. and K.W. Axhausen (2002) Measuring the size and structure of human activity spaces - the longitudinal perspective, Arbeitsbericht Verkehrs- und Raumplanung, 135, Institut für Verkehrsplanung und Transportsysteme (IVT), ETH Zürich, Zürich.

Schwarze, B. and Schönfelder, S. (2001) ArcView-Extension VISAR - Visualisierung von Aktionsräumen, Version 1.6, Arbeitsbericht Verkehrs- und Raumplanung, 95, Institut für Verkehrsplanung, Transporttechnik, Strassen- und Eisenbahnbau, ETH Zürich.

Sheffi, J. (1985) Urban Transportation Networks, Prentice Hall, Englewood Cliffs.

Silverman, B. W. (1986) Density Estimation for Statistics and Data Analysis, Chapman and Hall, London.

Southwood, T.R.E. and P.A. Henderson (2000) Ecological Methods, Blackwell Science, Oxford.

Zahavi, Y. (1979) The ,UMOT“ Project, US Department of Transportation RSPA-DPB, 20-79-3, US Department of Transportation, Washington.

Zimmermann, A., K.W. Axhausen, K.J. Beckmann, M. Düsterwald, E. Fraschini, T. Haupt, A. König, A. Kübel, G. Rindsfüser, R. Schlich, S. Schönfelder, A. Simma and T. Wehmeier (2001) Mobidrive: Dynamik und Routinen im Verkehrsverhalten: Pilotstudie Rhythmik, Report to Bundesministerium für Forschung und Technologie, PTV AG, Institut für Verkehrsplanung, Transporttechnik, Strassen- und Eisenbahnbau (ETH Zürich) and Institut für Stadtbauwesen (RWTH Aachen), Karlsruhe, Zürich and Aachen. 

Die Arbeitsberichte Verkehrs- und Raumpla- The Working Papers Transport and Spatial nung dienen der schnellen Verbreitung der Planning are intended for the quick disErgebnisse der Arbeit der Mitarbeitenden und semination of the results of the members Gäste des Instituts. Die Verantwortung für In- and guests of the Institute. Their content is halt und Gestaltung liegt alleine bei den $\mathrm{Au}-$ the sole responsibility of the authors. tor/innen.

Eine vollständige Liste der Berichte kann A complete catalogue of the papers can be vom Institut angefordert werden: obtained from:

IVT ETHZ

ETH Hönggerberg (HIL)

$$
\text { CH - } 8093 \text { Zürich }
$$

$$
\begin{array}{cc}
\text { Telephon: } & +41(0) 16333105 \\
\text { Telefax: } \quad+41(0) 16331057 \\
\text { E-Mail: } \quad \text { hotz@ivt.baug.ethz.ch } \\
\text { WWW: }
\end{array}
$$

Der Katalog kann auch abgerufen werden The catalogue can also be obtained from: von:

http://www.ivt.baug.ethz.ch/veroeffent_arbeitsbericht.html 